\title{
Overdiagnosing Vascular Dementia using Structural Brain Imaging for Dementia Work-Up
}

\author{
Ellis Niemantsverdriet ${ }^{\mathrm{a}, 1}$, Bart F.E. Feyen ${ }^{\mathrm{a}, \mathrm{c}, 1}$, Nathalie Le Bastard ${ }^{\mathrm{a}, \mathrm{e}}$, Jean-Jacques Martin ${ }^{\mathrm{a}}$, \\ Johan Goeman ${ }^{\mathrm{b}}$, Peter Paul De Deyn ${ }^{\mathrm{a}, \mathrm{b}, \mathrm{d}}$ and Sebastiaan Engelborghs ${ }^{\mathrm{a}, \mathrm{b}, *}$ \\ ${ }^{a}$ Reference Center for Biological Markers of Dementia (BIODEM), Laboratory of Neurochemistry and Behavior, \\ and Biobank, Institute Born-Bunge, University of Antwerp, Antwerp, Belgium \\ ${ }^{\mathrm{b}}$ Department of Neurology and Memory Clinic, Hospital Network Antwerp, Middelheim and Hoge Beuken, Antwerp, \\ Belgium \\ ${ }^{\mathrm{C}}$ Current affiliation: Department of Neurosurgery, Hospital Network Antwerp, Middelheim, Antwerp, Belgium \\ ${ }^{\mathrm{d}}$ Department of Neurology and Alzheimer Research Center, University of Groningen and University Medical Center \\ Groningen (UMCG), Groningen, The Netherlands \\ ${ }^{\mathrm{e}}$ Current affiliation: Fujirebio Europe, Ghent, Belgium
}

Handling Associate Editor: Piotr Lewczuk

Accepted 15 January 2015

\begin{abstract}
Hypothesizing that non-significant cerebrovascular lesions on structural brain imaging lead to overdiagnosis of a vascular etiology of dementia as compared to autopsy-confirmed diagnosis, we set up a study including 71 patients with autopsyconfirmed diagnoses. Forty-two patients in the population (59\%) appeared to have definite Alzheimer's disease (AD), whereas $29(41 \%)$ had a non-AD dementia form. The panel clinically diagnosed possible or probable vascular dementia (VaD) in 27 (38\%) patients, whereas only five (19\%) patients $(p=0.017)$ had an autopsy-confirmed diagnosis of VaD. Patients with vascular lesions on structural brain imaging were often misdiagnosed as possible or probable VaD as compared to autopsy-confirmed diagnosis.
\end{abstract}

Keywords: Alzheimer's disease, brain imaging, dementia, differential dementia diagnosis, magnetic resonance imaging, vascular dementia

\section{INTRODUCTION}

By performing a clinical diagnostic dementia work-up in elderly patients, frequently concomitant diseases or abnormalities on technical examinations

\footnotetext{
${ }^{1}$ These authors contributed equally to this work.

${ }^{*}$ Correspondence to: Prof. Dr. Sebastiaan Engelborghs, UAntwerp, Universiteitsplein 1, BE-2610 Antwerp, Belgium. Tel.: +32 3265 2631; Fax: +32 3265 2669; E-mail: Sebastiaan. Engelborghs@uantwerpen.be.
}

are observed [1,2]. It is often difficult to judge whether these concomitant factors are clinically relevant and thus contribute to the dementia syndrome. This is especially the case with ischemic lesions on structural brain imaging in elderly, which leads to difficulties to differentiate between Alzheimer's disease (AD), vascular dementia $(\mathrm{VaD})$, and $\mathrm{AD}$ with clinically significant cerebrovascular disease (CVD) [3, 4]. The diagnosis of $\mathrm{VaD}$, and its differentiation from $\mathrm{AD}$, is based on the presence of vascular risk factors, neuroimaging, 
and clinical features such as acute onset and stepwise progression.

In order to test the hypothesis that non-significant cerebrovascular lesions on structural brain imaging lead to overdiagnosis of a vascular etiology of dementing disorders, this study determined the clinical dementia diagnosis of a standard dementia work-up as compared to autopsy-confirmed diagnoses.

\section{MATERIALS AND METHODS}

\section{Study population}

Seventy-one demented patients with autopsyconfirmed diagnoses were included. Patients were recruited through the Memory Clinic of Hospital Network Antwerp $(n=64)$ and through centers referring to the Biobank of the Institute Born-Bunge $(n=7)$. Based on a presentation (by BF) of the information gathered during the clinical diagnostic work-up at enrollment in the study, a panel of three neurologists experienced with dementia (JG, PPDD, SE) made a consensus clinical dementia diagnosis. The panel was blinded for the clinical diagnoses that were mentioned in the clinical files of the included patients as well as for the neuropathological diagnoses. The panel was provided with clinical information, such as date of birth, age, gender, history of past illnesses, social history, onset and history of presenting complaint, familial history, medication, physical examination, clinical neurological examination, a complete neuropsychological examination including (among others) Mini-Mental State Examination scores (MMSE) [5], brain magnetic resonance imaging (MRI), and/or computed tomography (CT) scan.

This study was approved by the ethics committee of the UAntwerp, Antwerp, Belgium.

\section{Clinical diagnostic criteria}

Clinical diagnoses were based on standard clinical diagnostic criteria, allowing the panel to label each clinical diagnosis as probable or possible depending on the likelihood of it being the cause of dementia.

The diagnosis of probable AD was made according to the NINCDS-ADRDA criteria [6]. The combination of $\mathrm{AD}$ and $\mathrm{CVD}$ was diagnosed when patients fulfilled the criteria of probable AD according to NINCDSADRDA and, in addition, displayed CVD on brain CT and/or MRI that, however, did not meet the criteria of relevant CVD according to NINDS-AIREN criteria of [7], thus excluding multiple large-vessel infarcts, strategically placed infarcts, multiple basal ganglia, and white matter lacunes or extensive white matter lesions. VaD was diagnosed according to the NINDSAIREN criteria [7]. For the diagnosis of probable frontotemporal dementia (FTD), criteria described by Neary [8] were applied. Dementia with Lewy bodies (DLB) was diagnosed using the clinical diagnostic criteria of McKeith [9]. Parkinson's disease dementia (PDD) was diagnosed when patients with idiopathic Parkinson's disease (PD) developed dementia following a dementia-free interval of at least two years. The criteria for the diagnosis of idiopathic PD included the presence of at least two out of four motor manifestations that characterize the disease and an insidious onset [10]. Creutzfeldt-Jakob disease (CJD) was diagnosed according to the diagnostic criteria of Weber [11].

\section{Neuropathological criteria}

All pathological diagnoses were established according to standard neuropathological criteria by the same neuropathologist (JJM). Although the neuropathologist was blinded for the consensus diagnoses of the clinical panel, he had access to all neuroimaging data. For the diagnosis of $\mathrm{AD}, \mathrm{VaD}$, and DLB the neuropathological criteria of Montine [12] were applied. FTD was neuropathologically diagnosed according to the Cairns criteria [13] and Mackenzie criteria [14, 15]. CJD was diagnosed according to Markesbery [16]. Neuropathology was performed on the right hemisphere of the brain.

\section{Categorization of diagnoses}

Subjects neuropathologically diagnosed as AD or $\mathrm{AD}$ with $\mathrm{CVD}$ were pooled in the $\mathrm{AD}$ group whereas $\mathrm{VaD}$ and other dementias were pooled in the NONAD group.

\section{Statistical analyses}

To describe and analyze our entire cohort categorical variables were analyzed with a chi-square test, and percentages were reported. Demographic comparisons were analyzed with unpaired $t$-tests, or in case of no normal distribution a Mann Whitney U test was used, and mean values with standard deviation were reported. For all analyses, $p$-values below 0.05 were considered significant. All statistical analyses were performed using IBM SPSS Statistics 20. 


\section{RESULTS}

\section{Population (Table 1)}

Of the 71 patients, 38 were male $(54 \%)$ and 33 were female $(46 \%)$. There was no significant difference in the proportion of gender in the $A D$ and NONAD patient groups. Definite AD was diagnosed in 42 patients $(59 \%)$, whereas $29(41 \%)$ patients had a NONAD dementia: $\operatorname{VaD}(n=6)$, FTD $(n=9)$, DLB $(n=10)$, and CJD $(n=4)$. The NONAD group was significantly younger than the AD group, for both age at inclusion and age at death. MMSE scores were not significantly different comparing both groups. The interval between inclusion and autopsy was in most cases short (as $66 \%$ of the patients died within one year following inclusion), likewise as the interval between last clinical evaluation and autopsy. No significant differences were observed comparing intervals between inclusion/last clinical evaluation and autopsy between AD and NONAD groups. Structural neuroimaging data were available for all patients: CT $(n=47)$ or MRI $(n=24)$ brain scans.

\section{Clinical dementia diagnoses as compared to autopsy-confirmed definite dementia diagnoses}

In total, six patients were neuropathologically diagnosed with $\mathrm{VaD}(8 \%)$. The panel clinically diagnosed possible or probable VaD in $27(38 \%)$ patients (with or without concomitant AD or DLB). Of those 27 patients, diagnosis of $\mathrm{VaD}$ was neuropathologically confirmed in only five (19\%) patients $(p=0.017$, Fig. 1). The other neuropathologically confirmed VaD patient was diagnosed during the clinical work-up as probable AD/possible DLB and did not show clinically relevant vascular disease according to the panel. During the seven month interval between inclusion in this study and death, no clinically overt symptoms of stroke had occurred in this patient.
The neuropathological diagnoses of five clinically diagnosed probable $\mathrm{VaD}$ patients was definite $\mathrm{AD}$ $(n=3)$ and definite DLB $(n=2)$. None of the cases that were clinically diagnosed as probable $\mathrm{VaD}$ were neuropathologically confirmed as VaD. Fourteen patients were clinically diagnosed as probable $\mathrm{AD}+$ possible $\mathrm{VaD}$. However, neuropathologically, only two patients were diagnosed as $\mathrm{VaD}$ whereas the others were diagnosed as $\mathrm{AD}(n=7)$, FTD $(n=4)$, and DLB $(n=1)$. Lastly, eight clinical differential diagnoses consisted of probable $\mathrm{VaD}$ with another probable or possible dementia diagnosis, but only three of these were true $\mathrm{VaD}$ based on the neuropathological examination whereas the others were neuropathologically diagnosed as $\operatorname{AD}(n=3)$, FTD $(n=1)$ and $\operatorname{DLB}(n=1)$.

\section{DISCUSSION}

In this study, patients with vascular lesions on structural brain imaging were often misdiagnosed as suffering of dementia with a presumed clinically significant vascular component as compared to the autopsy-confirmed diagnoses. After neuropathological confirmation, the majority of these subjects were diagnosed with other dementia types than $\mathrm{VaD}$. In particular, none of the patients clinically diagnosed as probable $\mathrm{VaD}$ were neuropathologically confirmed as such. A clinical diagnosis of possible $\mathrm{VaD}$ in combination with $\mathrm{AD}$ or another neurodegenerative brain disorder showed better correspondence of clinical diagnosis with the neuropathological diagnosis.

A possible explanation is that non-significant cerebrovascular lesions (not contributing to pathophysiology of the dementia syndrome) observed with structural imaging of the brain were clinically overrated. Moreover, by using structural brain imaging only to exclude other brain pathologies, neurodegenerative brain disorders may be overlooked. From this point of

Table 1

Description of the population

\begin{tabular}{|c|c|c|c|}
\hline & \multicolumn{2}{|c|}{ Pathological diagnosis } & \multirow[t]{2}{*}{ Statistical analyses } \\
\hline & $\mathrm{AD}$ & NONAD & \\
\hline Gender (\% male/female) (n) & $52 / 48(42)$ & $55 / 45(29)$ & $p=0.817$ \\
\hline Age at inclusion $(\mathrm{y})(\mathrm{n})$ & $80.1[ \pm 9.0](42)$ & $71.0[ \pm 11.5](29)$ & $p<0.001$ \\
\hline Age at death $(y)(n)$ & $82.0[ \pm 8.3](42)$ & $72.3[ \pm 11.3](29)$ & $p<0.001$ \\
\hline MMSE (score out of 30) (n) & $13.5[ \pm 6.3](36)$ & $16.0[ \pm 6.9](23)$ & $p=0.152$ \\
\hline Interval inclusion and autopsy (y) (n) & $1.7[ \pm 2.6](42)$ & $1.3[ \pm 1.6](29)$ & $p=0.944$ \\
\hline Interval last clinical evaluation and autopsy (y) (n) & $0.6[ \pm 1.7](42)$ & $0.5[ \pm 0.9](29)$ & $p=0.537$ \\
\hline
\end{tabular}

Data are mean [SD], percentage (\%), or number (n). 


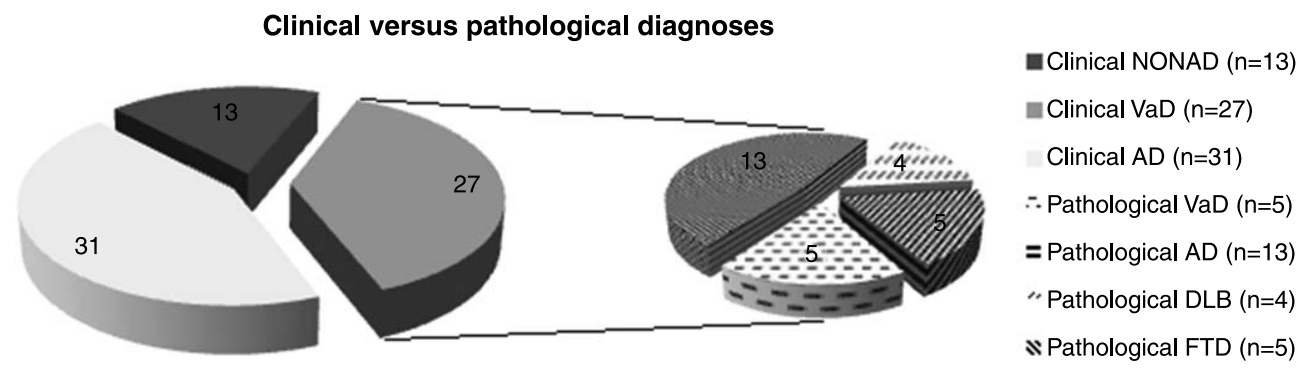

Fig. 1. Clinical diagnoses versus pathological diagnoses. The 27 clinically diagnosed cases with possible or probable VaD are subdivided into the different pathological diagnosis [ $\operatorname{VaD}(n=5), \mathrm{AD}(n=13)$, DLB $(n=4)$, or FTD $(n=5)]$.

view, structural brain imaging served as a confounder, leading to an overdiagnosis of $\mathrm{VaD}$.

A promising approach that might overcome structural brain imaging being a potential confounder is the use of biomarkers to diagnose dementia, including the rating of hippocampal atrophy on brain MRI scan [17]. The inclusion of biomarkers in the revised research criteria for $\mathrm{AD}$ diagnosis will significantly increase the clinical diagnostic accuracy [17-19], as well as the chance to identify $\mathrm{AD}$ pathophysiology in dementias of mixed origin and also in prodromal AD [20-23]. However, the issue of judging whether cerebrovascular lesions on structural brain imaging are pathophysiologically and clinically relevant, and thus, contribute to the dementia syndrome will remain. Furthermore, many factors that were identified as contributing to CVD are frequently suspected as predisposing to $A D$ as well, and therefore mixed dementias are probably underestimated [24].

The extensive use of CT scans (66\%) compared to MRI scans in this study could be a limitation of this study. However, when imaging would only have been performed by MRI, the proportion of misdiagnosed patients might have been increased to the increased detection of non-relevant cerebrovascular lesions as MRI is a more sensitive diagnostic method [25]. Another limitation of this study is that the clinical diagnosis was performed retrospectively, however, the panel of neurologists was blinded to neuropathological findings. Last but not least, the neuropathological examinations were only performed on the right hemispheres, and the fact that neuropathology is only a relative gold standard, could be seen as limitations of this study.

In conclusion, patients with vascular lesions on structural brain imaging were often misdiagnosed as possible or probable $\mathrm{VaD}$ as compared to the autopsy-confirmed diagnosis. The majority of these subjects were neuropathologically diagnosed with other dementia types than $\mathrm{VaD}$.

\section{ACKNOWLEDGMENTS}

This research was in part supported by the University Research Fund of the University of Antwerp; the Institute Born-Bunge; the central Biobank facility of the Institute Born-Bunge/University Antwerp; the Foundation for Alzheimer Research (SAO-FRA); Neurosearch Antwerp; the Research Foundation Flanders (FWO); the Agency for Innovation by Science and Technology (IWT); the Interuniversity Attraction Poles (IAP) programme of the Belgian Science Policy Office; the Flemish Government Methusalem excellence program, Belgium. This work is part of the BIOMARKAPD project within the EU Joint Program for Neurodegenerative Disease Research (JPND). This work has received support from the EU / EFPIA Innovative Medicines Initiative Joint Undertaking (EMIF grant $\mathrm{n}^{\circ}$ 115372).

The authors acknowledge the administrative and the clinical staff of the Department of Neurology and Memory Clinic of Hospital Network Antwerp, Middelheim and Hoge Beuken, Antwerp, Belgium.

Authors' disclosures available online (http://jalz.com/manuscript-disclosures/14-2103r2).

\section{REFERENCES}

[1] Toledo JB, Arnold SE, Raible K, Brettschneider J, Xie SX, Grossman M, Monsell SE, Kukull WA, Trojanowski JQ (2013) Contribution of cerebrovascular disease in autopsy confirmed neurodegenerative disease cases in the National Alzheimer's Coordinating Centre. Brain 136, 2697-2706.

[2] Jellinger KA (2007) The enigma of vascular cognitive disorder and vascular dementia. Acta Neuropathol 113, 349-388.

[3] Shim YS, Roe CM, Buckles VD, Morris JC (2013) Clinicopathologic study of Alzheimer's disease: Alzheimer mimics. J Alzheimers Dis 35, 799-811.

[4] Jellinger K, Danielczyk W, Fischer P, Gabriel E (1990) Clinicopathological analysis of dementia disorders in the elderly. J Neurol Sci 95, 239-258.

[5] Van der Mussele S, Le Bastard N, Saerens J, Somers N, Marien P, Goeman J, De Deyn PP, Engelborghs S (2015) Agitationassociated behavioral symptoms in mild cognitive impair- 
ment and Alzheimer's dementia. Aging Ment Health 19, 247-257.

[6] McKhann G, Drachman D, Folstein M, Katzman R, Price D, Stadlan EM (1984) Clinical diagnosis of Alzheimer's disease: Report of the NINCDS-ADRDA Work Group under the auspices of Department of Health and Human Services Task Force on Alzheimer's Disease. Neurology 34, 939-944.

[7] Roman GC, Tatemichi TK, Erkinjuntti T, Cummings JL, Masdeu JC, Garcia JH, Amaducci L, Orgogozo JM, Brun A, Hofman A et al. (1993) Vascular dementia: Diagnostic criteria for research studies. Report of the NINDS-AIREN International Workshop. Neurology 43, 250-260.

[8] Neary D, Snowden JS, Gustafson L, Passant U, Stuss D, Black S, Freedman M, Kertesz A, Robert PH, Albert M, Boone K, Miller BL, Cummings J, Benson DF (1998) Frontotemporal lobar degeneration: A consensus on clinical diagnostic criteria. Neurology 51, 1546-1554.

[9] McKeith IG, Dickson DW, Lowe J, Emre M, O’Brien JT, Feldman H, Cummings J, Duda JE, Lippa C, Perry EK, Aarsland D, Arai H, Ballard CG, Boeve B, Burn DJ, Costa D, Del Ser T, Dubois B, Galasko D, Gauthier S, Goetz CG, Gomez-Tortosa E, Halliday G, Hansen LA, Hardy J, Iwatsubo T, Kalaria RN, Kaufer D, Kenny RA, Korczyn A, Kosaka K, Lee VM, Lees A, Litvan I, Londos E, Lopez OL, Minoshima S, Mizuno Y, Molina JA, Mukaetova-Ladinska EB, Pasquier F, Perry RH, Schulz JB, Trojanowski JQ, Yamada M, Consortium on DLB (2005) Diagnosis and management of dementia with Lewy bodies: Third report of the DLB Consortium. Neurology $\mathbf{6 5}$, 1863-1872.

[10] Hoehn MM, Yahr MD (1967) Parkinsonism: Onset, progression and mortality. Neurology 17, 427-442.

[11] Weber T (2000) Clinical and laboratory diagnosis of Creutzfeldt-Jakob disease. Clin Neuropathol 19, 249-250.

[12] Montine TJ, Phelps CH, Beach TG, Bigio EH, Cairns NJ, Dickson DW, Duyckaerts C, Frosch MP, Masliah E, Mirra SS, Nelson PT, Schneider JA, Thal DR, Trojanowski JQ, Vinters HV, Hyman BT, National Institute on A, Alzheimer's A (2012) National Institute on Aging-Alzheimer's Association guidelines for the neuropathologic assessment of Alzheimer's disease: A practical approach. Acta Neuropathol 123, 1-11.

[13] Cairns NJ, Bigio EH, Mackenzie IR, Neumann M, Lee VM, Hatanpaa KJ, White CL, 3rd, Schneider JA, Grinberg LT, Halliday G, Duyckaerts C, Lowe JS, Holm IE, Tolnay M, Okamoto K, Yokoo H, Murayama S, Woulfe J, Munoz DG, Dickson DW, Ince PG, Trojanowski JQ, Mann DM, Consortium for Frontotemporal Lobar D (2007) Neuropathologic diagnostic and nosologic criteria for frontotemporal lobar degeneration: Consensus of the Consortium for Frontotemporal Lobar Degeneration. Acta Neuropathol 114, 5-22.

[14] Mackenzie IR, Neumann M, Baborie A, Sampathu DM, Du Plessis D, Jaros E, Perry RH, Trojanowski JQ, Mann DM, Lee VM (2011) A harmonized classification system for FTLDTDP pathology. Acta Neuropathol 122, 111-113.

[15] Mackenzie IR, Neumann M, Bigio EH, Cairns NJ, Alafuzoff I, Kril J, Kovacs GG, Ghetti B, Halliday G, Holm IE, Ince PG, Kamphorst W, Revesz T, Rozemuller AJ, Kumar-Singh S, Akiyama H, Baborie A, Spina S, Dickson DW, Trojanowski JQ, Mann DM (2010) Nomenclature and nosology for neuropathologic subtypes of frontotemporal lobar degeneration: An update. Acta Neuropathol 119, 1-4.
[16] Markesbery WR (1998) Neuropathology of dementing disorders, Arnold.

[17] Dubois B, Feldman HH, Jacova C, Cummings JL, Dekosky ST, Barberger-Gateau P, Delacourte A, Frisoni G, Fox NC, Galasko D, Gauthier S, Hampel H, Jicha GA, Meguro K, O’Brien J, Pasquier F, Robert P, Rossor M, Salloway S, Sarazin M, de Souza LC, Stern Y, Visser PJ, Scheltens P (2010) Revising the definition of Alzheimer's disease: A new lexicon. Lancet Neurol 9, 1118-1127.

[18] McKhann GM, Knopman DS, Chertkow H, Hyman BT, Jack CR Jr, Kawas CH, Klunk WE, Koroshetz WJ, Manly JJ, Mayeux R, Mohs RC, Morris JC, Rossor MN, Scheltens P, Carrillo MC, Thies B, Weintraub S, Phelps $\mathrm{CH}$ (2011) The diagnosis of dementia due to Alzheimer's disease: Recommendations from the National Institute on Aging-Alzheimer's Association workgroups on diagnostic guidelines for Alzheimer's disease. Alzheimers Dement 7, 263-269.

[19] Albert MS, DeKosky ST, Dickson D, Dubois B, Feldman HH, Fox NC, Gamst A, Holtzman DM, Jagust WJ, Petersen RC, Snyder PJ, Carrillo MC, Thies B, Phelps CH (2011) The diagnosis of mild cognitive impairment due to Alzheimer's disease: Recommendations from the National Institute on Aging-Alzheimer's Association workgroups on diagnostic guidelines for Alzheimer's disease. Alzheimers Dement 7, 270-279.

[20] Engelborghs S (2013) Clinical indications for analysis of Alzheimer's disease CSF biomarkers. Rev Neurol (Paris) 169, 709-714.

[21] Silverman DH, Small GW, Chang CY, Lu CS, Kung De Aburto MA, Chen W, Czernin J, Rapoport SI, Pietrini P, Alexander GE, Schapiro MB, Jagust WJ, Hoffman JM, WelshBohmer KA, Alavi A, Clark CM, Salmon E, de Leon MJ, Mielke R, Cummings JL, Kowell AP, Gambhir SS, Hoh CK, Phelps ME (2001) Positron emission tomography in evaluation of dementia: Regional brain metabolism and long-term outcome. JAMA 286, 2120-2127.

[22] Shaw LM, Vanderstichele H, Knapik-Czajka M, Clark CM, Aisen PS, Petersen RC, Blennow K, Soares H, Simon A, Lewczuk P, Dean R, Siemers E, Potter W, Lee VM, Trojanowski JQ, Alzheimer's Disease Neuroimaging I (2009) Cerebrospinal fluid biomarker signature in Alzheimer's disease neuroimaging initiative subjects. Ann Neurol 65, 403413.

[23] Clark CM, Pontecorvo MJ, Beach TG, Bedell BJ, Coleman RE, Doraiswamy PM, Fleisher AS, Reiman EM, Sabbagh MN, Sadowsky CH, Schneider JA, Arora A, Carpenter AP, Flitter ML, Joshi AD, Krautkramer MJ, Lu M, Mintun MA, Skovronsky DM, Group A-AS (2012) Cerebral PET with florbetapir compared with neuropathology at autopsy for detection of neuritic amyloid-beta plaques: A prospective cohort study. Lancet Neurol 11, 669-678.

[24] Korczyn AD (2002) Mixed dementia-the most common cause of dementia. Ann N Y Acad Sci 977, 129-134.

[25] Beynon R, Sterne JA, Wilcock G, Likeman M, Harbord RM, Astin M, Burke M, Bessell A, Ben-Shlomo Y, Hawkins J, Hollingworth W, Whiting P (2012) Is MRI better than CT for detecting a vascular component to dementia? A systematic review and meta-analysis. BMC Neurol 12, 33. 